Cita bibliográfica: Batista de Lima, T. y Ferreira da Silva, J. (2018). Treinamento e hospitalidade: um estudo em hotéis de João Pessoa, Paraíba, Brasil. Investigaciones Turísticas (15), pp. 108-127. http://dx.doi.org/10.14198/ INTURI2018.15.05

\title{
Treinamento e hospitalidade: um estudo em hotéis de João Pessoa, Paraíba, Brasil
}

\author{
Training and hospitality: A study at Juan Pessoa hotels, Paraíba, Brazil \\ Formación y hospitalidad: un estudio en hoteles de Juan Pessoa, Paraíba, Brasil
}

Thales Batista de Lima. Universidad Federal de Paraíba. thalesufpb@gmail.com Joelma Ferreira da Silva. Universidad Federal de Paraíba. joellmaferreirards@gmail.com

\section{RESUMO}

A hospitalidade foi incorporada pela hotelaria e se tornou uma prática utilizada pelos hotéis para proporcionar atendimento diferenciado. Assim, o objetivo geral desta pesquisa é analisar a política de treinamento realizada por hotéis da capital paraibana para o desenvolvimento da hospitalidade. Desse modo, a fundamentação abordou os principais aspectos tipo, etapas, riscos e contribuições que envolvem treinamento, além da questão da hospitalidade e sua relevância no meio hoteleiro. Com relação à metodologia, utilizou-se a abordagem qualitativa, cujo método empregado foi o dedutivo e descritivo. Salienta-se que o estudo apresenta uma visão interpretativa dos dados. Dentre as principais constatações do estudo, observou-se que os treinamentos mais utilizados pelos hotéis são os de integração, comportamentais e técnicos, além disso, indica-se que a partir do treinamento, os gestores procuram pontuar a importância de tratar e receber bem os hóspedes. Quanto ao conhecimento dos gestores sobre o conceito de hospitalidade, percebeu-se que está relacionado ao ato do bem receber ou acolher. Portanto, conclui-se que os treinamentos aplicados pelos hotéis pesquisados contribuem para que a hospitalidade seja desenvolvida, resultando na melhoria do acolhimento dado aos hóspedes e, consequentemente, fazendo com que os empreendimentos ganhem destaque no cenário hoteleiro paraibano.

Palavras-chave: hotelaria; treinamento; gestores

\section{ABSTRACT}

Hospitality has been incorporated by the hotel industry and has become a practice used by hotels to provide a differentiated service. Thus, the overall objective of this research is to analyze a training policy carried out by hotels in the capital for the development of hospitality. Therefore, the basic principles such as the type, stages, risks and contributions of training are addressed as well as the question of hospitality and its relevance in the hotel environment. 
Regarding the methodology, a qualitative approach has been used with a deductive and descriptive method. Therefore, the study presents an interpretive view of the data. Among the main findings of the study, it was observed that the hotels mostly used integration, behavioural and technical training practices. The results also reveal that the training of managers highlights the importance given to the good treatment and welcoming of guests. Regarding the managers' knowledge about the concept of hospitality, it was found that they related it to the act of receiving or welcoming. Therefore, it may be concluded that the training implemented by the hotels taking part in the survey contributed to the development of hospitality, resulting in the improvement of the reception given to the guests and, consequently, consolidating the business ventures in the hotel scenario in Paraiba.

Keywords: hospitality; training; managers.

\section{RESUMEN}

La hospitalidad se ha convertido en una práctica utilizada por los hoteles para proporcionar atención diferenciada al cliente. El objetivo de esta investigación es analizar la política de formación y capacitación realizada por hoteles de la capital paraibana para el desarrollo de la hospitalidad. De este modo, se abordan los principales aspectos tipo, etapas, riesgos y contribuciones que involucran la formación, además de la cuestión de la hospitalidad y su relevancia en el medio hotelero. Con respecto a la metodología, se utilizó un enfoque cualitativo, cuyo método empleado fue el deductivo y descriptivo, de manera que el estudio presenta una visión interpretativa de los datos. Entre las principales conclusiones se encuentran que las prácticas formativas más utilizadas por los hoteles son la integración, comportamental y técnica. Por otra parte, a partir de la formación los gestores buscan puntuar la importancia de tratar y recibir bien los invitados. En cuanto al conocimiento de los gestores sobre el concepto de hospitalidad, se percibió que está relacionado al acto del bien recibir o acoger. Se concluye que la formación aplicada por los hoteles encuestados contribuye a que la hospitalidad progrese, resultando en la mejora de la acogida dada a los huéspedes y, consecuentemente, haciendo que las iniciativas empresariales se consoliden en el escenario hotelero paraibano.

Palabras clave: hospitalidad, formación, gestores.

\section{INTRODUÇÃO}

As organizações vêm apresentando grandes mudanças na sua estratégia de gestão com o intuito de se destacar no setor em que estão inseridas, visto que novos posicionamentos são incorporados, tanto em relação à excelência no atendimento e a fatores relacionados com a hospitalidade ao visitante, quanto no que tange à capacitação e ao treinamento dos profissionais para recebê-lo (TEIXEIRA, 2001; ASSMANN, 2012).

$\mathrm{Na}$ hotelaria, a hospitalidade é um fator relevante, inclusive, muitas organizações turísticas desenvolvem técnicas de atendimento voltadas ao bem-estar e ao acolhimento de seus hóspedes, pois este é um fator que vem se revelando como uma maneira para se obter resultados positivos perante a concorrência. É evidente que os hóspedes necessitam ser bem acolhidos, e isto certamente serve como um componente decisivo para o cliente no momento 
da escolha (ou não) de determinado hotel, conforme atentam Grinover, (2007) e Assmann (2012).

Assim, os profissionais que atuam no setor se enquadram em uma categoria, cuja capacitação contínua é visivelmente demandada. É comum associar a falta de hospitalidade ou o mau atendimento à falha no treinamento da organização para com os colaboradores, no entanto, salienta-se que a característica de ser hospitaleira, por vezes, é algo intrínseco em algumas pessoas, enquanto que outras já não trazem consigo virtudes vinculadas à hospitalidade.

Tendo em vista que o treinamento é o elemento que busca alterar o comportamento, proporcionar habilidades e desenvolver competências, nota-se a sua importância nos hotéis, visto que o sucesso destas organizações depende diretamente da boa relação entre funcionários e hóspedes. Portanto, o treinamento se refere a qualquer ação sistematizada que busca oferecer ao indivíduo conhecimentos e habilidades para o adequado desempenho de suas tarefas no cargo que ocupa, como assinalam Magalhães et al (2010). Rezende et al (2012) acrescenta que essa política surge da necessidade de manter a equipe de trabalho preparada para desempenhar efetivamente o seu papel do ambiente organizacional.

Entende-se que a função do treinamento consiste justamente em aprimorar o comportamento dos funcionários, direcionando-os para um melhor entendimento da relevância de encantar e fidelizar o cliente por meio do atendimento hospitaleiro. Sendo assim, este trabaIho objetiva analisar a política de treinamento realizada por hotéis da capital paraibana para o desenvolvimento da hospitalidade.

\section{FUNDAMENTAÇÃO TEÓRICA}

Para Lacombe (2006), treinamento é qualquer atividade que contribua para tornar uma pessoa apta a exercer a sua função ou atividade. Cada vez que o indivíduo proporciona uma orientação ou discute um procedimento, pode-se dizer que está treinando. Eboli (2004) já atribuía que o foco estava no saber, tendo como objetivo principal trabalhar o conhecimento e o saber fazer para melhorar o desempenho, baseado na tarefa em curto prazo. Para reforçar a conceituação em torno do treinamento, Milkovich e Boudreau (2000) conceituam-no como um processo sistemático que promove a aquisição de habilidades, regras, conceitos e atitudes que busquem a melhoria na adequação entre as características dos funcionários e as exigências dos papéis funcionais.

Na análise de Campos et al. (2004), o treinamento é um processo que auxilia o empregado a adquirir eficiência no seu trabalho presente ou futuro por meio de apropriados hábitos de pensamento. Doravante, Marras (2000) classifica os objetivos do treinamento como Específicos e Genéricos, envolvendo tais características:

- Formação profissional: que tem como base elevar o conhecimento do profissional à sua profissão, para elevar o seu desempenho nas suas atividades;

- Especialização: oferece a oportunidade de treinamentos, ao empregado, voltados a uma área de conhecimento específico; 
- Reciclagem: é a oportunidade de haver uma atualização dos conhecimentos já aprendidos na sua rotina de serviço.

Milkovich e Boudreau (2000), por sua vez, apontam quatro tipos de treinamento, são eles: de integração, que tem como objetivo adaptar as pessoas à organização; técnico-operacional, o qual busca capacitar o indivíduo para o desempenho das tarefas específicas a serem realizadas; comportamental, que tem como intuito solucionar os problemas das inter-relações no contexto do trabalho; e, por fim, o gerencial, que procura desenvolver a competência técnica, administrativa e comportamental. Por isso, Prahalad e Hamel (1990) alertam na década de 1990 sobre competências essenciais para melhorar a sustentabilidade do negócio. Isso se transfere para a necessidade de encontrar e desenvolver competências de gestores que conduzam a organização, o que ocorre por meio da aplicação de treinamentos para os mesmos. Isto é, a organização ganha vantagem competitiva através de competências essenciais que afetam o negócio. $E$ é sabido que as pessoas executam competências e podem ser direcionadas a desempenhar o que for de essencial sobre tal empreendimento, o que pode ser incentivado mediante a política de treinamento.

Já Chiavenato (2014) postula que as técnicas de treinamento são: leitura, instrução programada, treinamento em classe, computer-based training, e-leaning, sendo as suas técnicas classificadas quanto ao uso, ao tempo e ao local e se baseiam na aplicação da teoria de aprendizagem. Aguinis e Kraiger (2009) atentam que a política de treinamento precisa ser considerada a partir de uma qualidade multidimensional de suas necessidades, ou seja, as necessidades de treinamento são vistas em diferentes níveis singulares de análise. Assim, não é apenas a simples soma de necessidades de níveis inferiores ou particulares, cuja responsabilidade de todo o processo de treinamento diga respeito a um indivíduo ou grupo, mas é pertencente a uma noção multidimensional dos diversos agentes que compõem e se relacionam com a organização.

Além disso, o processo de treinamento consta em etapas que requerem ser conhecidas e planejadas para que a organização possa extrair o melhor possível dos funcionários e, assim, alcançar melhores resultados. Dessa forma, o processo praticado pelas organizações nos programas de treinamento se desenvolve, até hoje, a partir de basicamente quatro etapas: diagnóstico, planejamento e programação, execução e avaliação (MARRAS, 2000).

Segundo Noe (2015), o treinamento e desenvolvimento podem ser de responsabilidade de profissionais de recursos humanos. Pode-se dizer que em empresas pequenas, ele fica a cargo do fundador e de todos os funcionários. Já em organizações de médio ou grande porte, o treinamento pode ser responsabilidade de profissionais de recursos humanos, ou vir de uma função separada conhecida como desenvolvimento de recursos humanos, gestão de talentos, desenvolvimento, aprendizado ou desenvolvimento organizacional. A área de recursos humanos, nesse caso, é a viabilizadora dos treinamentos, ou seja, busca os meios para viabilizá-los, seja internamente ou com profissionais externos. Frisa-se que os gestores, em sua maioria, têm a responsabilidade de decidir quando os funcionários precisam de treinamento e de que forma ele será feito (ROBBINS, 2014).

Diante disto, entende-se que o treinamento em uma organização deve ser uma atividade constante e, mesmo quando as pessoas apresentam um bom desempenho, alguma 
orientação e melhoria das habilidades sempre deverá ser introduzida ou incentivada. No entanto, para que os programas de treinamento alcancem os objetivos traçados pela organização, é necessário o apoio de toda a gerência, pois cabe ao gestor avaliar o resultado da capacitação e o rendimento de cada colaborador. Contudo, mesmo tendo um papel fundamental nesse processo, alguns gestores ainda resistem à ideia de investir em preparação, por mais que esta torne a avaliação um momento salutar para gerar mais confiabilidade perante os gestores.

Segundo Carvalho e Nascimento (1997), a avaliação do treinamento trata de um conjunto de metodologias e procedimentos que possibilitam identificar os resultados obtidos com os programas desse exercício, comparando-os com os objetivos propostos. No entanto, Chiavenato (2001) afirma que ainda existem empresas que temem investir nisso, como também já foi falado em relação aos gestores. Muitos empresários ainda consideram o treino como uma despesa e não como forma de redução de custos e aumento da produtividade que pode trazer valiosas contribuições para a organização. Para Boog (2006), o temor das organizações pode estar relacionado à possibilidade de o funcionário sair da empresa e, no pior dos casos, migrar para a concorrência, o que seria considerada a primeira preocupação que os gestores têm ao pensar em investir em treinamento.

Segundo Lacombe (2005), o risco do investimento nesse exercício está na dificuldade de calcular retorno, pois ele sempre vem a longo prazo, mas o que se quer é o imediatismo. Para o autor, é preciso adotar medidas para minimizar os riscos, os quais, segundo Boog (2006), podem ser reduzidos por meio de algumas ferramentas, como planos de cargos e salários, pois buscam comprometer mais os funcionários com a empresa.

Na percepção de Oliveira e Gueiros (2004), em uma organização hoteleira o treinamento das pessoas deve ser permanente porque ele aprimora o desempenho pessoal e eleva o nível de competitividade da empresa, portanto, ele necessita estar de acordo com as estratégias organizacionais. Lacerda e Abbad (2003) compartilham dessa mesma visão e observam-no como um processo de aprendizagem contínua que proporciona a melhoria da performance do funcionário dentro da organização.

Para Miranda (2008), o setor hoteleiro deve estar preocupado com o treinamento dos profissionais contanto que ele seja mais direcionado às questões da hospitalidade ao hóspede, visto que é importante que os funcionários sejam bem orientados e estimulados a praticar a hospitalidade para que, assim, eles possam desenvolver maneiras de receber a todos os clientes com satisfação e cordialidade.

Destaca-se que a relação da hospitalidade com a hotelaria é antiga, uma vez que Lane e Dupré (1997) afirmam que durante o governo de Hamurabi, no antigo império Babilônico, de 1792 a 1750 a.C, já existiam os serviços de hotelaria, quando ali surgiram as primeiras leis que regulamentavam as atividades dos lugares que hospedavam pessoas. Na Grécia antiga, a hospitalidade e outros serviços ligados ao que hoje se compreende como serviços turísticos e da hotelaria já estavam presentes no cotidiano grego.

Costa (2015) recorda que a hospitalidade já foi um dever sagrado, moral e social de algumas sociedades antigas, cuja atitude que dava início ao acolhimento, hoje em dia tem sentidos novos. Pode-se falar nela como uma característica comercial, na qual para Lashley e 
Morrison (2004), é desenvolvida pelo setor hoteleiro com normas voltadas a atingir a qualidade e o bom atendimento e, assim, viessem a suprir as necessidades do hóspede.

Gondim (2008) argumenta que na hotelaria, apesar da enorme importância de os empreendimentos ofertarem instalações físicas de qualidade, o principal produto oferecido por eles se caracteriza pela intangibilidade, ou seja, não pode ser visto, provado ou sentido e consiste na hospitalidade e no "calor humano" dos serviços prestados pelos profissionais da área aos seus clientes. Portanto, nas organizações hoteleiras, a hospitalidade se insere como uma prática que deve ser desenvolvida pelos funcionários para que eles possam estar prontos para receber os hóspedes da melhor forma possível.

Segundo Camargo (2004), nos dias atuais essa recepção se configurou como objeto de estudo em diversas áreas, como filosofia e sociologia, por exemplo. Por conta disto, surgiram diferentes tendências em sua análise. $O$ autor defende a existência de duas escolas para 0 estudo da hospitalidade: uma francesa e a outra, americana. Na escola francesa, acredita-se na hospitalidade como dar, receber e retribuir, sem foco no lado comercial, enquanto na visão americana, a ela é apresentada justamente como uma versão comercial, fundamentada num contrato e na troca.

Já de acordo com Lashley (2004), a hospitalidade pode ser analisada sob os domínios social, privado e comercial, sendo que o domínio social considera os cenários sociais e a hospitalidade e os atos ligados a ela ocorrem na sociedade e na convivência humana. $\mathrm{Na}$ visão de Michelin e Araújo (2014), a ela é intrinsecamente ligada às relações humanas e é melhor desenvolvida no campo dos serviços turísticos por propiciar a convivência entre as pessoas em atos de trocas de bens materiais e simbólicos. Grinover (2007), em sua análise sobre a importância da hospitalidade no turismo, bem como na hotelaria, alega que o fato de estas atividades se caracterizarem pela prestação de serviços às pessoas, elas envolvem sentimentos, experiências, como também bens e produtos tangíveis e intangíveis. Assim, muitas organizações turísticas buscam ser comercialmente hospitaleiras, desenvolvendo técnicas de atendimento voltadas ao bem-estar em receber seus clientes ou hóspedes.

Para Albuquerque e Santos (2008), a hospitalidade "sustenta" a competitividade das organizações que desejam satisfazer, encantar e proporcionar boas experiências aos clientes. E esse desejo deve ser compartilhado por todos que constituem a empresa, entretanto, é preciso que haja um esforço e uma orientação entre todos os envolvidos com o meio de hospedagem, independentemente do nível hierárquico, a fim de que a hospitalidade seja percebida pelo hóspede em todos os setores.

Portanto, percebe-se que para que o setor hoteleiro satisfaça as necessidades dos hóspedes, surpreendê-los pela excelência do serviço prestado e pelo atendimento realizado com hospitalidade são aspectos importantes. A emoção de ser bem recebido e de ter suas expectativas superadas deixa o hóspede com uma boa impressão do meio de hospedagem e isso pode se tornar um diferencial a partir do momento em que forem oferecidos aos clientes não apenas acomodações, mas também a preocupação com o seu bem-estar. 


\section{METODOLOGIA}

O estudo tem uma abordagem qualitativa, na qual Creswell (2010) define como sendo um meio para explorar e compreender o significado que os indivíduos atribuem a um problema social ou humano. Segundo Godoy (1995), a pesquisa qualitativa envolve a obtenção de dados descritivos sobre pessoas e lugares, sem necessariamente enumerar ou mensurar quantitativamente as características e comportamentos da situação em estudo. Ou seja, o foco desse tipo de pesquisa está na interpretação do fenômeno investigado, sob a perspectiva dos participantes, ao invés da quantificação Enquanto para Bicudo (2000), a investigação qualitativa se caracteriza por privilegiar, essencialmente, a compreensão dos fenômenos através de narrativas verbais dos sujeitos.

Os sujeitos da pesquisa são constituídos pelos gestores de 3 (três) hotéis localizados na orla marítima de João Pessoa - PB, que estão situados entre os bairros de Cabo Branco, Tambaú e Manaíra. Vale ressaltar que a escolha dos meios de hospedagem teve como critério o tempo de atuação no mercado ou ainda pertencer a uma rede, para, justamente, ter um contraponto da forma com a qual o treinamento é ministrado em um hotel com menor e maior tradição mercadológica e sendo administrado por uma rede. Sendo assim, o hotel de Manaíra tem 8 anos de mercado, com 140 UHs e 299 leitos. Já o hotel localizado no bairro de Tambaú, foi inaugurado em 1971, tendo 46 anos de atuação no mercado hoteleiro de João Pessoa, com 173 UHs e 306 leitos. Por sua vez, o hotel situado no Cabo Branco pertence a uma rede hoteleira, cuja unidade pesquisada está há pouco mais de 2 anos no mercado, apresentando 88 UHs e os leitos variam entre 190 e 240, dependendo da ocupação porque, geralmente, disponibilizam camas extras, berços e sofás cama. Frisa-se que esta unidade é a sétima da rede na capital paraibana, que tem um total de 8 unidades na cidade.

Desse modo, a presente pesquisa foca em três gestores, seguindo, respectivamente, o critério estabelecido na seleção dos hotéis. A seguir, apresenta-se o perfil dos entrevistados, conforme a tabela 1, denominados pela letra " $E$ " e depois por um número que o identifica, do qual segue sequencialmente do "E1" até "E3":

Tabela 1. Perfil dos entrevistados

\begin{tabular}{|c|c|c|l|l|l|}
\hline Gestor & Idade & Sexo & \multicolumn{1}{|c|}{ Formação } & Tempo na empresa & \multicolumn{1}{|c|}{ Cargo atual } \\
\hline E1 & 20 & F & Ciências Contábeis & 3 anos e 3 meses & $\begin{array}{l}\text { Assistente de } \\
\text { desenvolvimento } \\
\text { humano }\end{array}$ \\
\hline E2 & 35 & M & Turismo & 12 anos & Chefe de recepção \\
\hline E3 & 32 & F & Psicologia & 1 ano e 3 meses & $\begin{array}{l}\text { Gerente de } \\
\text { recursos humanos }\end{array}$ \\
\hline
\end{tabular}

Fonte: Elaborado pelos autores (2016)

O instrumento de coleta de dados utilizado foi o roteiro de entrevista semiestruturada, a qual Marconi e Lakatos (2011) postulam que permite ao pesquisador maior liberdade para 
desenvolver cada situação, dando direcionamento que considere adequado, e, assim, explorar mais amplamente a questão que se está pesquisando.

O processo de análise seguiu os passos indicados por Silva (2005) na direção da compreensão do fenômeno: transcrição das entrevistas, codificação dos discursos e categorização.

Depois dessa divisão e codificação, os discursos foram classificados em categorias e as categorias agrupadas em temáticas, conforme o exposto no quadro a seguir:

Quadro 1. Temáticas e categorias

\begin{tabular}{|c|l|}
\hline Temáticas & \multicolumn{1}{c|}{ Categorias } \\
\hline \multirow{3}{*}{ Caracterização do treinamento } & - Tipos de treinamento \\
& - Periodicidade e abrangência \\
& - Responsáveis pelo treinamento \\
\hline Treinamento e Hospitalidade & - Importância do treinamento \\
\hline Hospitalidade & - Implicações do treinamento na hospitalidade \\
\hline & - Definições e aspectos de hospitalidade \\
& - Retorno sobre hospitalidade \\
\hline
\end{tabular}

Fonte: Elaborado pelos autores (2016)

Depois destas etapas, foi realizada a análise proposta por Silva (2005), que são a compreensiva e interpretativa dos dados. Portanto, a pesquisa buscou correlacionar os relatos dos entrevistados entre eles e confrontar os resultados obtidos com as teorias que serviram de embasamento para o trabalho, a fim de atender a questão principal do trabalho, que trata da análise da política de treinamento utilizada pelos hotéis pesquisados da capital paraibana para o desenvolvimento da hospitalidade.

\section{ANÁLISE E DISCUSSÃO DOS RESULTADOS}

\subsection{Caracterização do treinamento}

É fundamental caracterizar como a política de treinamento é praticada nos hotéis da capital paraibana, a partir da visão dos gestores de cada hotel para, posteriormente, compreender a sua relação com a hospitalidade.

\subsubsection{Tipos de Treinamento}

Essa categoria visa a dissertar sobre os treinamentos oferecidos pelos hotéis aos colaboradores, a fim de ampliar e desenvolver suas habilidades. Para isto, conforme Milkovich e Boudreau (2000), existem quatro tipos de treinamento que podem ser realizados em diferentes situações e finalidades, são eles: de integração, comportamental, técnico-operacional e gerencial. Sendo assim, quando indagados sobre essas capacitações aplicadas pela organização foi exibido que: 
A gente aplica treinamentos técnicos e treinamentos comportamentais. A gente fez agora de todo front, de toda recepção. Fez treinamento com o recepcionista, com o gerente de recepção, com mensageiro e garagista. Todos eles foram treinados para as funções técnicas que eles desempenham, fora os treinamentos comportamentais. (E3.1)

Percebe-se que há uma preocupação do gestor em realizar treinamentos que facilitem a execução dos procedimentos, o que permite um melhor aproveitamento das habilidades operacionais do colaborador. Lacombe (2005) explica que a (capacitação) de integração consiste basicamente em apresentar ao novo colaborador os objetivos, as políticas, as estratégias, os produtos, os benefícios e uma série de normas da empresa, como pode ser observado na fala do entrevistado (E1.2): "Quando eles chegam, eles vão se integrar à empresa, conhecer as pessoas e quais são as regras internas: o que ele pode, o que ele não pode, tanto as regras normais, quanto as regras de segurança". Há também similaridade com relação a este tipo de treinamento no depoimento do E2:

Logo que a pessoa entra aqui conosco no hotel, nós fazemos um treinamento, ela quando chega aqui, ela conhece os apartamentos para poder saber o que ela vai falar com o hóspede. Ela conhece todas as categorias, fica um dia de treinamento com a governadoria, depois passa um período também com o pessoal de reservas. (E2.1)

Sendo assim, proporcionar treinamentos aos colaboradores é um fator positivo, seja para integrar os funcionários recém contratados ou ampliar habilidades práticas relacionadas às competências úteis para desempenhar as funções no hotel, pois eles estando capacitados, estas funções podem ser cumpridas com mais segurança e eficiência. De acordo com Oliveira e Gueiros (2004), em uma organização hoteleira, o treinamento aprimora o desempenho pessoal e eleva o nível de competitividade da empresa. Para que isso ocorra, é imprescindível que o treinamento escolhido esteja alinhado às estratégias organizacionais do hotel.

\subsubsection{Periodicidade e Abrangência}

Um aspecto relevante no processo de treinamento consiste no planejamento das ações que serão implementadas. Nesse caso, alguns pontos devem ser levados em consideração, sendo eles: a extensão dos programas, quantos e com que frequência deverão ser aplicados e quais setores serão atingidos (MARRAS, 2000).

De acordo com os relatos dos gestores entrevistados, com relação à periodicidade do treinamento, nota-se que depende muito dos objetivos organizacionais de cada hotel. 0 entrevistado E2 declara que o treinamento é realizado uma única vez, mas quando surge algo novo a ser apresentado para os colaboradores, vê-se a necessidade de aplicar um novo treinamento, como pode ser constatado abaixo:

Treinamento propriamente dito a gente faz uma vez, a não ser que tenha alguma coisa a ser implantada para a equipe, que a gente faz um treinamento coletivo. Por exemplo, teve agora a questão do cartão eletrônico nos apartamentos, então 
foi um treinamento coletivo, todos tiveram participação nesse treinamento. (E2.2)

Já no hotel gerenciado pelo entrevistado E3, os treinamentos são realizados em diferentes setores e constantemente durante o ano, como demonstrado em sua fala:

Ocorre por setor, a gente treina o pessoal de front, recepção, manutenção, governança. A gente passa o ano todo aplicando treinamentos e anualmente cada setor vai passando por esse treinamento novamente e ele vai sendo reajustado e atualizado. (E3.2)

Por fim, o entrevistado E1 relata que o hotel passa por modificações e, por conta disto, os treinamentos serão aplicados em todos os setores, mas anualmente, como dito em seu discurso.

Todo setor tem mapeado suas atividades e todos recebem treinamento. Nós estamos passando por algumas mudanças, então sempre tínhamos treinamentos todos os anos, mas agora a gente vai ter no primeiro ano: todos os treinamentos, no segundo ano: não tem treinamento, no terceiro ano é avaliado e no quarto ano começa um novo (E1.6).

Nesse processo de mudanças, o treinamento tem um papel fundamental, no sentido de preparar os colaboradores para estas reformulações. Willumsen (2006) afirma que na hotelaria o treinamento deve ser realizado com todos os colaboradores e de maneira constante, visto que é um ramo no qual a excelência da qualidade no serviço está diretamente relacionada à capacitação da equipe. Portanto, percebe-se que os gestores visam desempenhar os treinamentos em todos os setores e a frequência em que são realizados está pautada nos objetivos que os hotéis pretendem atingir.

\subsubsection{Responsáveis pelo treinamento}

Outro fator pertinente na implantação de um treinamento é a escolha de quem deverá aplicá-lo. Robbins (2014) ressalta que cabe aos gestores a responsabilidade de decidir quando os funcionários precisam de treinamento e de que maneira ele será feito. Já para Noe (2015), a área de recursos humanos é quem viabiliza as ações de treinamento.

Dessa forma, em todos os hotéis analisados, o treinamento é realizado pelo pessoal interno, como afirmam os entrevistados: "Pelas lideranças e pelo $\mathrm{DH}$, a maioria são pelas lideranças e alguns pelo DH" (E1.9). Semelhantemente, outro entrevistado diz: "Isso, isso pelo pessoal interno em relação ao treinamento propriamente dito da área, é feito de forma interna" (E2.3). O outro gestor apresenta pensamento parecido, como o expresso a seguir: "Ele é aplicado pelo pessoal interno e pelo RH" (E3.3).

Portanto, o treinamento é desenvolvido por pessoas internas, uma vez que isso facilita que os próprios gestores juntamente com o departamento de recursos humanos elaborem de forma mais precisa as informações que serão transmitidas para os colaboradores, por estarem familiarizados com o dia a dia e as rotinas do hotel. 


\subsubsection{Avaliação}

Avaliar o treinamento significa mensurar os resultados obtidos e comparar com o que foi planejado pelo hotel. É também uma oportunidade para investigar se os conteúdos repassados estão sendo utilizados e o quanto desse treinamento contribuiu para a melhoria do desempenho do colaborador e, consequentemente, na qualidade do serviço ofertado. Milkovich e Boudreau (2000) salientam que, muitas vezes, a avaliação não é realizada, o que acaba se tornando um aspecto negativo, visto que esta é uma parte essencial para certificar tanto o retorno sobre o investimento, quanto para dar subsídio a decisões futuras.

Sendo assim, quando questionados sobre a maneira pela qual os resultados dos treinamentos são avaliados, o entrevistado E1 relata que o método utilizado está sujeito ao tipo de treinamento que é aplicado, tendo em vista que a avaliação é preparada por meio de uma prova ou observação, como visto em seu discurso: "Pode ser com uma prova ou observação, vai depender do treinamento" (E1.8). Esta mesma metodologia é empregada pelo entrevistado E3, como se observa no trecho "A gente aplica avaliações" (E3.4). Quando o treinamento é aplicado com o colaborador da linha de frente, a avaliação é realizada pelo gestor de forma mais detalhada através de métodos específicos do hotel, como exposto na fala do entrevistado E1:

Nós temos o QSE, o QSE é um checklist sobre a postura que a liderança preenche observando o atendimento do colaborador, e não só a forma de atender, mas se ele está fardado, se chamou o cliente pelo nome porque a gente já sabe qual o nome do cliente, se está com o crachá, se está com a aparência "ok", se deu todas as informações do check-in, se foi cordial, simpático, se buscou resolver os problemas, a gente avalia se ele ainda pratica tudo aquilo que ele aprendeu, se houver necessidade, a gente pode retreinar ou conversar com a pessoa. (E1.8)

Similarmente, o entrevistado E3 diz: "No dia a dia a gerência vai acompanhando quem realmente assimilou, quem não, e quem vai precisar de um reforço em relação ao treinamento" (E3.4). Desse modo, pelos discursos dos gestores, nota-se que alguns dos critérios utilizados para mensurar os resultados vão ao encontro dos apontados por Bohlander e Snell (2009) como: avaliações de aprendizado e comportamento do colaborador, observações e registro de informações, que permitem que o gestor identifique os aspectos positivos ou até negativos do treinamento aplicado e, a partir disto, determine medidas corretivas ou mesmo retreinamento.

Dessa maneira, foi visto no quesito de como é realizado o processo do treinamento nos hotéis, que os gestores são participativos durante todo o procedimento e que são eles juntamente com o departamento de recursos humanos que fazem o levantamento das necessidades da aplicação do treinamento e avaliam a frequência em que este é realizado e em quais setores do hotel. Assim, nota-se que há interesse dos hotéis em capacitar os colaboradores para que eles possam contribuir de forma efetiva na qualidade do serviço proposto por cada empreendimento. 


\subsection{Treinamento e hospitalidade}

Sabe-se que na hotelaria a hospitalidade é um fator pertinente, o que é evidenciado pela forma que as pessoas que atuam no hotel recebem os hóspedes. Para isto, como dito por Miranda (2008), os funcionários precisam ser bem orientados e estimulados a praticá-la e os treinamentos devem ser direcionados a esta questão.

\subsubsection{Importância do treinamento}

Nesta parte, serão analisadas as atribuições do treinamento para o setor hoteleiro na visão dos gestores e se são percebidas melhorias no desempenho dos colaboradores, decorrentes da sua aplicação. Dessa forma, pelo depoimento dos entrevistados, ficou exposto que o treinamento é tido como uma ferramenta essencial para alinhar os procedimentos e garantir a qualidade no atendimento, como pode ser visto nas falas do entrevistado E3.

Acho que é primordial, senão você não vai seguir procedimentos. O treinamento é primordial para alinhar. A gente hoje tem 8 hotéis na rede, então o cara que é atendido em um lá em Cabo Branco, ele é do mesmo jeito atendido lá em Tambaú, Campina Grande, enfim, aonde ele for é o mesmo, graças ao treinamento. [...] A gente percebe o quanto isso é importante em relação a seguir qualidade no atendimento [...] então você só consegue garantir essa qualidade mediante treinamento. (E3.5, E3.12, E3.6)

O entrevistado E1 expõe que sem o treinamento os colaboradores não desempenhariam de forma correta alguns procedimentos e, por conta disto, haveria inúmeras reclamações, como relatado em seu discurso:

Se não tivesse os treinamentos, com certeza a gente teria várias reclamações: ah! Não fui atendido direito, a pessoa não foi cordial ou virou as costas para mim na recepção, o que a gente não permite aqui. Se eles não fossem treinados para isso, eles não fariam da forma correta, então é essencial, não tem como não ter. (E1.10)

Enquanto isso, para o entrevistado E2 o treinamento é fundamental para engrandecer o conhecimento da área que o profissional atua, como se pode confirmar na reprodução da sua fala: "Fundamental, acho que tudo que é aprendizado, tudo que é treinamento ele é bem-vindo, só faz engrandecer o seu currículo para aquela área que você está" (E2.5).

\subsubsection{Implicações do treinamento na hospitalidade}

A hospitalidade é uma ferramenta que viabiliza um atendimento de qualidade em um meio de hospedagem, logo, os gestores devem sempre buscar meios que direcionem os colaboradores a compreender o quanto atitudes hospitaleiras agregam no processo de acoIhimento do hóspede. No entender de Brotherton e Wood (2004), a hospitalidade pode ser compreendida como uma motivação comportamental, se tornando possível associá-la às práticas de gestão de pessoas, visto mais recente da existência de treinamentos comportamentais focados essencialmente na melhoria das relações. 
Assim, buscou-se compreender se os gestores percebem influências do treinamento na maneira que os colaboradores recebem os hóspedes e como eles dirigem essa capacitação voltada à questão da hospitalidade. Dessa forma, pelos comentários dos entrevistados, todos afirmam visualizar melhorias decorrentes da aprendizagem adquirida pelos funcionários após o investimento, feito pelos empresários, no modo pelo qual os hóspedes deveriam ser tratados no ambiente de acolhimento, como demonstrado na explicação do entrevistado E2: "Com certeza, a gente percebe uma evolução no quadro da pessoa, a gente percebe sim" (E2.15). Já o entrevistado E3, fala: "Com certeza, todo mundo fica bem mais afiado nesse sentido e eu acrescento mais: não existe a hipótese de a operação atuar hoje sem estar sendo treinada constantemente". (E3.12). Por fim, o entrevistado E1 é sucinto em dizer que "Sim, com certeza" (E1. 22).

Quando questionados em como são direcionados os treinamentos voltados à hospitalidade, o entrevistado E3 declara:

Não tem como nenhum dos treinamentos da gente não ser voltado à hospitalidade. A gente está lidando com o ramo hoteleiro, então todos os nossos treinamentos são voltados à questão da hospitalidade, desde o treinamento de uma camareira, de um recepcionista, todos são focados para isto, independentemente de ser técnico ou comportamental, o foco da rede é isso a hospitalidade. (E3.6)

Já o entrevistado E1, afirma que o valor da hospitalidade é alimentado durante a aplicação do treinamento, como visto em seu discurso: "Quando a gente ministra um treinamento, a gente reforça a importância de cuidar e servir, a importância de tratar bem o cliente, então eles percebem que a forma correta de trabalhar é sempre ser cordial” (E1. 23). Por sua vez, o entrevistado E2 procura orientar os colaboradores por meio do diálogo, o que para Lacombe (2006) também se caracteriza como um treinamento, pois à medida que você discute um procedimento, oferece uma orientação, você está treinando. Quanto ao discurso do E2, ele comenta: "Eu falo muito com eles, eu dialogo muito com eles assim: veja do outro lado do balcão como se fosse você que tivesse do outro lado sendo atendido, dê o melhor de si" (E2.6). Ele acrescenta ainda que a hospitalidade é algo que dever ser exercitado e que pode ser aprendido e faz uma analogia interessante com o ato de dirigir, como ele exprime abaixo:

A hospitalidade tem que ser fomentada, tem que ser desenvolvida, tem que ser praticada no dia a dia. Ninguém nasce sabendo, você não nasce sabendo receber bem. Alguns têm uma habilidade maior para isso, você não nasceu aprendendo a dirigir, você precisou de um treinamento, algumas pessoas dirigem melhor que as outras, mas todas podem aprender. Você pode aprender tudo: a dirigir, a receber bem e quanto mais fomentar isso melhor você vai ficando (E2.16).

Percebe-se pelos discursos dos entrevistados que o treinamento tem um papel preponderante na disseminação da cultura hospitaleira dentro dos hotéis pesquisados, pois treinar os colaboradores faz parte da arte do bem receber. Por conseguinte, é imprescindível que os gestores invistam em práticas de treinamento, tendo em vista que o processo de acoIhimento depende das pessoas, pois, vale salientar, que são elas que propagam a imagem do hotel diariamente então, se o empreendimento tiver como prioridade as normas voltadas à 
hospitalidade e o bom atendimento, as estratégias devem ser voltadas a lapidar e desenvolver as habilidades e o comportamento dos colaboradores neste sentido.

\subsection{Hospitalidade}

Desde os primórdios, das primeiras civilizações, regras que norteavam as formas de receber e oferecer hospitalidade aos hóspedes começavam a ser concebidas. Esse termo frequentemente é associado à hotelaria para descrever as atividades relacionadas ao modo de acolher e satisfazer o visitante. Lashley (2004) alega que a hospitalidade tem significados amplos, mas entendê-los é essencialmente útil para que se possam administrar os serviços.

\subsubsection{Definições e aspectos de hospitalidade}

Nesta categoria são analisados os conceitos atribuídos à hospitalidade de acordo com os gestores e quais aspectos são vistos por eles como prioritários para recepcionar de maneira hospitaleira. Assim sendo, pelos depoimentos dos entrevistados, percebe-se que a maioria dos conceitos apontados está relacionada à intangibilidade do serviço hoteleiro, como a simpatia, o bem receber e o acolhimento diferenciado, como demonstrado na fala dos entrevistados E1: "Acolher os clientes de maneira diferenciada" (E1.15) e E2: ", hospitalidade é o ato de receber. Quando você vai pra um hotel, o que você quer?. Você vai procurar aquela pessoa que tem o melhor sorriso pra lhe atender e se ela lhe atender bem, com certeza você vai querer voltar pra aquele hotel e ser atendido pela aquela pessoa ou aquela camareira X. Isso é hospitalidade, é o bem atender" (E2.9) e E3:"a hospitalidade é isso, é o receber bem" (E3.8).

Quando questionados sobre quais aspectos caracterizavam a hospitalidade ofertada pelo hotel, o entrevistado E3 aponta uma combinação de quesitos tangíveis e intangíveis, como visto em sua fala:

Como é que eu recebo bem uma pessoa dentro de um hotel? Primeiro, atendimento, segundo, limpeza do ambiente, terceiro, alimentação que seja diferenciada, um bom café da manhã, toda uma ação que seja voltada para aquela pessoa que está chegando. E para receber bem em um hotel, você precisa atender esses requisitos (E3.8).

Já para o entrevistado E1, os elementos principais quando se deseja receber de forma hospitaleira são um somatório de atitudes do anfitrião, como evidenciado em seu discurso: "Cordialidade, antecipar o problema do cliente, proatividade e simpatia. Se não tiver estas três coisas, você acaba pecando em alguma coisa" (E1.16). Por sua vez, o entrevistado E2 relata que sorrir, ser cortês e educado é essencial antes mesmo de o hóspede entrar na recepção do hotel, como explica abaixo:

Um bom sorriso, educação, cortesia, desde lá do início da rampa, que é quando o mensageiro vai abordar com educação desejando um bom dia, boa tarde, boa noite com um sorriso, perguntando se a viagem foi boa, conversando sendo educado, dando seu melhor sorriso, dando o melhor de si (E2.7). 
Dessa forma, pode-se compreender que para os gestores as conceituações de hospitalidade estão ligadas ao bem receber ou acolher, e os aspectos evidenciados por eles como sendo característicos em uma recepção hospitaleira permeiam entre uma mistura harmoniosa de componentes tangíveis e intangíveis que, aliás, se iguala ao entendimento de autores da área do turismo, como Lashley (2004), o qual destaca que a hospitalidade é alcançada por meio da disponibilidade de acomodação, alimentos e bebidas. E Castelli (2006), que enfatiza o sorriso como um dos maiores traços da hospitalidade, pois consegue ser entendido por todos. $\mathrm{E}$, assim, com todas essas ações, o hóspede tende a enxergar o hotel como hospitaleiro.

\subsubsection{Retorno sobre hospitalidade}

Sabe-se que a experiência do acolhimento nos lugares visitados muitas vezes é responsável pela construção de uma imagem positiva ou negativa daquele local. Erig e Nascimento (2015) alegam que o atendimento e as formas de acolher o visitante é atualmente a preocupação das empresas do setor turístico. Quadros (2011) lembra que a hospitalidade é um importante componente na relação entre o hotel e seus clientes e, por vezes, acaba sendo um diferencial. Nesse sentido, esta categoria busca dissertar sobre o quanto na visão dos gestores o exercício dessa atitude garante o desenvolvimento do hotel.

Portanto, de acordo com os discursos dos entrevistados, pode-se afirmar que a hospitalidade representa um atributo primordial no segmento, como dito pelo entrevistado E3.

Com certeza! É primordial num negócio, se eu não tratar a hospitalidade como meu ponto chave principal no topo, eu estou tratando o negócio errado. Então é sim primordial para rede, é o que faz o negócio girar, é o que faz a dinâmica acontecer na hotelaria é a hospitalidade, não tem como pensar em hotelaria, sem pensar em hospitalidade, não existe essa possibilidade. (E3.13)

Já o entrevistado E2, coloca que mais que um diferencial, a hospitalidade é o patrimônio do hotel, sendo um ponto relevante para fidelizar os clientes, como ele exprime abaixo:

De certa forma é um patrimônio da empresa a hospitalidade [...] Tem gente que vem pra cá que falou que nunca foi tão bem atendido num hotel como aqui, e voltam pra cá várias vezes. Eu tenho hóspede que vem pra cá todo final de ano porque só quer passar o fim de ano aqui e pessoas que têm grana pra passar um fim de ano em Nova Iorque, Dubai na Austrália, Japão, onde quiser ela passa o fim de ano, mas ela passa aqui porque ela gosta da hospitalidade daqui, do bom atendimento daqui. Todo ano procuram, ligam para cá, mandam e-mail (E2.16, E2.11).

Por sua vez, o entrevistado E1 fala que a "Hospitalidade é o nosso cargo chefe, é algo primordial, crucial. Eu não volto em lugares onde sou mal recebida, a mesma coisa com cliente, se você não se sente bem, não se sente importante naquele lugar, você não volta [...] Todo hóspede que chega, é recebido com uma taça de água de coco e esses pequenos detalhes fazem com que ele se sinta em casa, e é o que vai fazer a pessoa voltar" (E1. 24, E1.13)

Portanto, percebe-se a hospitalidade como um elemento trabalhado pelos gestores e que é considerado primordial em cada hotel, visto que se torna um fator que permite a 
possibilidade de os hóspedes retornarem aos empreendimentos. Pode-se dizer que sem praticar a hospitalidade, a hotelaria não tem como se sustentar, pois certamente um hotel só conseguirá se sobressair no mercado se aliar a prestação de bons serviços às experiências de acolhimento com hospitalidade.

Posteriormente é apresentado um quadro explicitando as categorias e seus devidos significados a partir dos relatos dos entrevistados.

Quadro 2. Significado das Categorias

\begin{tabular}{|c|l|}
\hline Categoria & \multicolumn{1}{c|}{ Significado } \\
\hline Tipos de Treinamento & $\begin{array}{l}\text { Proporcionar treinamentos aos colaboradores é um fator muito positivo, } \\
\text { pois observou-se que todos os hotéis nos aplicam e os mais utilizados são } \\
\text { os de integração, comportamentais e técnicos. }\end{array}$ \\
\hline $\begin{array}{c}\text { Periodicidade e } \\
\text { abrangência }\end{array}$ & $\begin{array}{l}\text { Percebeu-se que os gestores visam desempenhar os treinamentos em } \\
\text { todos os setores, no entanto, a frequência em que são realizados está } \\
\text { pautada nos objetivos que cada hotel pretende atingir. }\end{array}$ \\
\hline $\begin{array}{c}\text { Responsáveis pelo } \\
\text { treinamento }\end{array}$ & $\begin{array}{l}\text { Os treinamentos em todos os hotéis são aplicados pelo pessoal interno, } \\
\text { ou seja, pelos gestores, juntamente com o departamento de recursos } \\
\text { humanos e/ou desenvolvimento humano. }\end{array}$ \\
\hline $\begin{array}{c}\text { Avaliação } \\
\text { Importância do } \\
\text { treinamento }\end{array}$ & $\begin{array}{l}\text { Avaliar os resultados obtidos com o treinamento é essencial para que se } \\
\text { possa investigar se os conteúdos repassados estão sendo utilizados e o } \\
\text { quanto desse treinamento contribuiu para a melhoria do desempenho } \\
\text { do colaborador. Logo, todos os hotéis realizam a mensuração desses } \\
\text { resultados por meio de avaliações e observando o comportamento dos } \\
\text { colaboradores. }\end{array}$ \\
\hline $\begin{array}{c}\text { Refinições e aspectos } \\
\text { de hospitalidade }\end{array}$ & $\begin{array}{l}\text { De maneira geral, todos os entrevistados julgaram o treinamento como } \\
\text { uma ferramenta primordial para o setor hoteleiro, pois por meio dessa } \\
\text { política é possível alinhar procedimentos específicos da hotelaria. É } \\
\text { evidente a evolução do desempenho dos colaboradores em decorrência } \\
\text { dos conteúdos passados nos treinamentos. }\end{array}$ \\
\hline $\begin{array}{c}\text { Implicações do } \\
\text { treinamento na } \\
\text { hospitalidade }\end{array}$ & $\begin{array}{l}\text { Para os gestores, o treinamento tem um papel importante na } \\
\text { disseminação da cultura hospitaleira dentro dos hotéis, visto que treinar os } \\
\text { colaboradores faz parte da arte do bem receber e todos procuram investir } \\
\text { em seus colaboradores visando desenvolver a excelência nos serviços e no } \\
\text { atendimento hospitaleiro. }\end{array}$ \\
\hline um bom café da manhã e a limpeza dos ambientes.
\end{tabular}

Fonte: Elaborado pelos autores (2016) 


\section{CONCLUSÃO}

O presente trabalho procurou analisar a política de treinamento realizada por hotéis da capital paraibana para desenvolver a hospitalidade. Os três meios de hospedagem escolhidos seguiram o critério de tempo de participação no mercado, e o fato de eles serem administrados por uma rede, ou seja, foi selecionado um hotel com menor e maior atuação mercadológica e outro pertencente a uma rede. Dessa maneira, buscou-se inicialmente caracterizar a política de treinamento utilizada por estes hotéis, apontar como ocorre a importância dessa política para a melhoria da hospitalidade e a percepção dos gestores entrevistados a respeito do conhecimento sobre ela e o retorno de seu treinamento para o hotel.

Assim, com relação à caracterização dos treinamentos, os mais utilizados pelos hotéis são os de: integração, para familiarizar os colaboradores com particularidades do hotel; os comportamentais, visando estimulá-los a melhorar características do comportamento e os técnicos para facilitar a execução dos procedimentos. Os gestores são os responsáveis por realizar estes treinamentos e procuram aplicar principalmente o comportamental e o técnico em todos os setores, no entanto, a frequência em que são realizados depende dos objetivos pretendidos, das situações ocorridas no hotel, com as quais os gestores identifiquem a necessidade de aplicá-los, ou os já previstos em cronograma. Já a avaliação dos resultados dos treinamentos, segundo os gestores, é realizada por meio de exames/testes e da observação do comportamento dos colaboradores.

No que se refere à importância dessa política para a melhoria da hospitalidade, constatou-se que com o treinamento, os gestores procuram pontuar a importância de tratar e receber bem os hóspedes e, por conta disto, afirmam que há evolução no desempenho dos colaboradores em decorrência dos conteúdos passados na capacitação, pois a personalização e a excelência do atendimento é algo prezado pelos hotéis. E para que essa excelência aconteça, a prática do treinamento, conforme os gestores, se torna fundamental.

Quanto à percepção dos gestores a respeito do conhecimento sobre a hospitalidade, foi percebido que para os gestores o conceito de hospitalidade está relacionado ao ato do bem receber ou acolher e os aspectos evidenciados por eles como sendo característicos em uma recepção hospitaleira estão em demonstrar simpatia, acolhendo sempre com sorriso, e tendo cuidado no preparo das refeições e na limpeza dos ambientes. Por fim, em resposta ao treinamento voltado à hospitalidade, o principal retorno obtido é o regresso dos hóspedes aos meios de hospedagem em virtude do atendimento hospitaleiro recebido.

Portanto, de maneira geral, observou-se que o treinamento contribui de modo positivo para que os valores relacionados à hospitalidade comercial sejam desenvolvidos nos hotéis pesquisados. No entanto, analisando individualmente os discursos dos entrevistados, foi possível constatar algumas diferenças em relação à forma com a qual as ações de treinamento são direcionadas nos três tipos de hotéis para atingir esses resultados positivos: no hotel pertencente à rede, assim como no que está há menos tempo no mercado, o treinamento é planejado de maneira mais formal, tendo em vista que os gestores demonstraram maior preocupação quanto à periodicidade em que são aplicados, mas também em avaliar os resultados e em procurar incrementar conteúdos repassados. Já no hotel com atuação maior no setor, 
embora existam práticas de treinamento, o aprendizado acontece, na maioria das ocasiões, informalmente, por meio do diálogo.

Para futuras pesquisas, recomenda-se que sejam realizados mais estudos que relacionem as práticas de gestão de pessoas ao setor hoteleiro. No que tange ao treinamento, sugere-se que novas pesquisas contemplem a análise da efetividade e da importância dessa política na perspectiva dos colaboradores, além de aprofundar o tema em estudos de caso, no que tange aos distintos meios de hospedagem.

\section{REFERÊNCIAS BIBLIOGRÁFICAS}

Albuquerque, V. L. A. R de; Santos. C. H. S. (2008) Hospitalidade: um estudo de caso do hotel serrano de gramado/RS. Revista Rosa dos Ventos, Gramado, v. 1, n. 1, p.3-11, out.

Aguinis, H.; Kraiger, K. (2009). Benefits of training and development for individuals and teams, organizations, and society. Annual Review of Psychology, 60, 451-474.

Assmann, F. (2012) Comunicação, cultura e organizações hoteleiras: um estudo da hospitalidade em hotéis de Porto Alegre. 2012. 99 f. TCC (Graduação) - Curso de Comunicação Social, Universidade Federal do Rio Grande do Sul, Porto Alegre.

Bicudo, M. A. V. A. (2000) Pesquisa qualitativa fenomenológica à procura de procedimentos rigorosos. Fenomenologia: confrontos e avanços. São Paulo: Cortez.

Boog, G.G. (2006) Manual de treinamento e desenvolvimento: processos e operações. - São Paulo: Pearson Prentice Hal.

Bohlander, G.; Snell, S. (2009) Administração de Recursos Humanos. 14.ed. São Paulo: Cengage Learning.

Brotherton, B.; Wood, R.C. (2004) Hospitalidade e administração da hospitalidade. In: LASHLEY, C.; MORRISON, A. (orgs.). Em busca da hospitalidade: perspectivas de um mundo globalizado. São Paulo: Manole.

Camargo, L. O. L de. (2004) Hospitalidade. 2. ed. São Paulo: Aleph, Coleção ABC do Turismo.

Castelli, G. (2006) Gestão Hoteleira. Editora Saraiva: São Paulo.

Carvalho, A.v.; Nascimento, L.P. (1997) Administração de Recursos Humanos. V. 1. São Paulo: Pioneira.

Campos, K. C. L. et al. (2004) Avaliação do sistema de treinamento e desenvolvimento em empresas paulistas de médio e grande porte. Psicologia Reflexões e Critica, Porto Alegre. v.17, n.3, p.435-446.

Creswell, J. W. W. (2010) Projeto de pesquisa: métodos qualitativo, quantitativo e misto. 2. ed. Porto Alegre: Bookman.

Chiavenato, I. (2001) Desempenho humano nas organizações: Como desenhar cargos e avaliar o desempenho 5.ed. São Paulo: Atlas.

Chiavenato, I. (2014) Gestão de pessoas: O novo papel dos recursos humanos nas organizações. 4 ed. Barueri: São Paulo.

Costa, E.R.C. (2015) Comensalidade: a dádiva da hospitalidade através da gastronomia. Cultura - Revista de Cultura e Turismo, Ilhéus. v. 02, n. 9, p.54-69, jun.

Eboli, M. (2004) Educação Corporativa no Brasil: mitos e verdades. São Paulo: Gente. 
Erig, G. A; Nascimento, M. (2015) Hospitalidade como fator competitivo em agências de viagens e turismo na cidade de Palmas/TO. Revista de Turismo Contemporâneo, Natal, v. 3, n. 1, p.36-53, jun.

Grinover, L. (2007) A hospitalidade, a cidade e o turismo. São Paulo: Alpeh.

Gondim, C. B. (2008) Competências gerenciais relevantes e em desenvolvimento no setor hoteleiro de João Pessoa - PB. 2008. 203 f. (Dissertação) - Mestrado em Administração, Universidade Federal da Paraíba, João Pessoa.

Godoy, A. S. (1995) A pesquisa qualitativa e sua utilização em administração de empresas. Revista de Administração de Empresas, v. 35, n. 4, p. 65-71.

Lane, H.; DUPRÉ, D. (1997) Mundo da hospitalidade! Uma introdução. EUA: Van Nostrand Reinhold.

Lacombe, F. J. M. (2005) Recursos Humanos: princípios e tendências. São Paulo: Saraiva.

Lacombe, F. J. M. (2006) Recursos Humanos: princípios e tendências São Paulo: Saraiva.

Lacerda, E.r.m.; Abbad, G. (2003) Impacto do treinamento no trabalho: investigando variáveis motivacionais e organizacionais como suas preditoras. Revista de Administração Contemporânea, Rio de Janeiro, v. 7, n. 4, p. 77-96.

Lashley, C; Morrison, A. (2004) Em Busca da Hospitalidade: Perspectivas para um Mundo Globalizado. Barueri: Manole.

Magalhães, E. M.; Oliveira, A. R.; Cunha, N. R. S.; Lima, A. A. T. F. C.; Campos, D. C. S. (2010) A política de treinamento dos servidores técnicos administrativos da Universidade Federal de Viçosa na percepção dos treinados e dos dirigentes da instituição. Revista de Administração Pública. Rio de Janeiro/RJ, ed. 44.

Marconi, M. de A.; Lakatos, E. M. (2011) Metodologia científica. 6.ed. São Paulo: Atlas.

Marras, J. P. (2000) Administração de Recursos Humanos: do operacional ao estratégico. 3 a ed. São Paulo: Futura.

Michelin, R.I.; Araújo, C. D. (2014) Turismo e hospitalidade: informações turísticas Rodoviária Internacional de Boa Vista. Revista Rosa dos Ventos, Boa Vista, v. 6, n. 1, p.19-33, mar.

Miranda, L.C. de. (2008) Hotelaria brasileira: Hospitalidade como vantagem competitiva. In: IV Congresso Nacional de Excelência em Gestão. Niterói, RJ.

Milkovich, G. T.; Boudreau, J. W. (2000) Administração de Recursos Humanos. São Paulo: Atlas. Noe. A, R. (2015) Treinamento e desenvolvimento de pessoas. Amgh Editora, [ S.I: s.n ].

Oliveira, L. M.; Gueiros, M.G. (2004) Clientes internos satisfeitos com as práticas de RH conduzem à satisfação dos clientes externos? In: XXVIII Encontro Anual da Associação Nacional de Pós-graduação e Pesquisa em Administração. Enanpad. Curitiba, PR.

Prahalad, C. K.; Hamel, G. (1990) The Core Competence of the Corporation. Harvard Business Review, United States, $n^{\circ} 3$, p.79-91, may/june.

Quadros, H. A. (2011) A Hospitalidade e o diferencial competitivo das empresas prestadoras de serviço. Revista Hospitalidade, v.8, n. 1.

Rezende, J. L.; Schmidt, A. S.; Rinaudo, R.; Ferreira, J. L. D. (2012) O treinamento de pessoal em organizações de pequeno porte: um estudo de caso na cidade de Maringá. Revista Ciências da Administração. V. 18, n. 2. Fortaleza.

Robbins, S.P. (2014) A nova administração. São Paulo: Editora Saraiva. 
Silva, A.B. (2005) A vivência de conflitos entre a prática gerencial e as relações sem família. 2005. 272 f. (Tese) Doutorado em Engenharia de Produção - Centro Tecnológico, Universidade Federal de Santa Catarina, Florianópolis.

Teixeira, R. M. (2001) Ensino superior em turismoe hotelaria no Brasil: um estudo exploratório. Turismo e Análise, ECA/USP, v.12, n.2 nov. 2001. São Paulo.

Willumsen, V. C. (2006) Proposta de treinamento motivacional para os colaboradores do Hotel Faial como fator diferencial para a excelência na prestação de serviços. 2006. 103 f. TCC (Graduação) - Curso de Turismo e Hotelaria, Universidade Vale do Vale do Itajaí, São José. 